\title{
Quantitative multiparameter prediction of fault-related fractures: a case study of the second member of the Funing Formation in the Jinhu Sag, Subei Basin
}

\author{
Jing-Shou Liu ${ }^{1,2,3,4} \cdot$ Wen-Long Ding ${ }^{1,2,3,4} \cdot$ Jun-Sheng Dai ${ }^{5}$ Yang Gu ${ }^{1} \cdot$ Hai-Meng Yang ${ }^{6}$. \\ Bo Sun $^{7}$
}

Received: 7 November 2017 / Published online: 11 July 2018

(c) The Author(s) 2018

\begin{abstract}
In this paper, the analysis of faults with different scales and orientations reveals that the distribution of fractures always develops toward a higher degree of similarity with faults, and a method for calculating the multiscale areal fracture density is proposed using fault-fracture self-similarity theory. Based on the fracture parameters observed in cores and thin sections, the initial apertures of multiscale fractures are determined using the constraint method with a skewed distribution. Through calculations and statistical analyses of in situ stresses in combination with physical experiments on rocks, a numerical geomechanical model of the in situ stress field is established. The fracture opening ability under the in situ stress field is subsequently analyzed. Combining the fracture aperture data and areal fracture density at different scales, a calculation model is proposed for the prediction of multiscale and multiperiod fracture parameters, including the fracture porosity, the magnitude and direction of maximum permeability and the flow conductivity. Finally, based on the relationships among fracture aperture, density, and the relative values of fracture porosity and permeability, a fracture development pattern is determined.
\end{abstract}

Keywords Fault-related fracture - Quantitative prediction · Development pattern · Multiscale fracture $\cdot$ Numerical simulation · Jinhu Sag

\section{Introduction}

In the oil- and gas-producing areas of eastern China, tectonic fractures in reservoirs are closely related to the degree of fault development, and the formation mechanisms of

Edited by Jie Hao

Jing-Shou Liu

liujingshou@126.com

$\triangle$ Wen-Long Ding

Dingwenlong2006@126.com

1 School of Energy Resources, China University of Geosciences, Beijing 100083, China

2 Key Laboratory for Marine Reservoir Evolution and Hydrocarbon Abundance Mechanism, Ministry of Education, China University of Geosciences, Beijing 100083, China

3 Beijing Key Laboratory of Unconventional Natural Gas Geology Evaluation and Development Engineering, China University of Geosciences, Beijing 100083, China faults and tectonic fractures are relatively consistent (Zhang et al. 2004; Jiu et al. 2013a; Liu et al. 2016). The spatial relationship between higher-order faults and lowerorder faults provides insight into predicting fault-related fractures. Challenges related to the exploration and development of fractured oil reservoirs include evaluating the distribution and degree of fracture development in the

4 Key Laboratory for Shale Gas Exploitation and Assessment, Ministry of Land and Resources, China University of Geosciences, Beijing 100083, China

5 School of Geosciences, China University of Petroleum, Qingdao 266580, Shandong, China

6 Oil Recovery Plant No. 3, Zhongyuan Oilfield Co. Ltd, SINOPEC, Puyang 457001, Henan, China

7 CNOOC Energy Technology and Services-Drilling and Production Co., Tianjin 300452, China 
reservoirs and quantitatively predicting fracture porosity and permeability (Zeng and Li 2009; Hennings et al. 2012). Fractures play a dual role in oil and gas exploration: They increase the permeability of reservoirs and can even provide basic permeability and reservoir porosity within reservoirs (Wang et al. 2016b; Gong and Rossen 2017), but the presence of fractures can complicate oil and gas EOR injection processes and well network deployment (Cook et al. 2008; Laubach et al. 2009; Olson et al. 2009; Wang et al. 2016a; Soleimani 2017).

Similar to faults, fractures exist at various scales (Prioul and Jocker 2009; Strijker et al. 2012; Chen et al. 2016), and the flow capacities of fractures at different scales are different (Fan et al. 2017). To the best of our knowledge, few studies on the quantitative prediction of fractures have focused on the scaling properties of fractures and the evaluation and classification of flow capacity. In regions with multiple groups of fractures and multiple scales of fracture development, the prediction of the predominant direction of fracture-related seepage is a difficult problem (Liu et al. 2015). Many researchers (Mynatt et al. 2009; Brogi 2011; Walker et al. 2011; Jiu et al. 2013b; Fang et al. 2017; Liu et al. 2017a, 2018a; Pan et al. 2017) have focused on the timing, distribution, and formation mechanisms of fractures. In this paper, based on the similarity of faults and fractures, we predict areal fracture densities at different scales and develop a skewed distribution model of fracture apertures from cores. Furthermore, we apply the in situ stress field to analyze the apertures of underground fractures at different scales. By developing a mathematical model to characterize the fracture porosity and permeability, we quantitatively calculate the porosity and permeability of multiperiod and multiscale fractures. Based on the relationship between the aperture and the density of the fractures and the relative magnitudes of the fracture porosity and permeability, the development pattern of fractures in the Jinhu Sag is determined. The results are important for the practical demands of oil field exploration and development.

\section{Prediction of the areal density of fractures at different scales}

In this paper, we use the reservoirs in the second member of the Funing Formation in the Jinhu Sag as a case study. The Jinhu Sag is located in the western part of the Subei Basin and extends from the Jianhu Uplift in the northwest to the Tianchang Uplift in the south and from the Zhangbaling Uplift in the west to the two low Lingtiangqiao and Liubao Uplifts in the east (Fig. 1a). The Jinhu Sag formed gradually and became deeper in the south and shallower in the north. The southern area is faulted with a northward stratigraphic overlap pattern that developed during the deposition of the Funing Formation (Fig. 1b). The lithologies of the reservoirs in the second member of the Paleogene Funing Formation, which is the primary target formation, are mainly argillaceous siltstone, siltstone and fine sandstone, all of which have low permeability. Many years of exploration has confirmed the existence of large oil and gas resources in these reservoirs. The patterns of the oil and gas development programs in the Shigang, Qiaohekou, Biandong, Minqiao, Yangjiaba and Tongcheng regions are closely related to the spatial distribution and degree of development of fractures (Neng et al. 2009, 2012; Ji et al. 2010; Liu et al. 2015).

\subsection{Development features of fractures in the Jinhu Sag}

Based on observations and statistical analyses of fractures in cores from more than 50 wells in the Biandong, Shigang, Qiaohekou, Minqiao, Yangjiaba and Tongcheng regions of the Jinhu Sag, we determined that tectonic fractures are well developed in the reservoirs of the second member of the Funing Formation ( $\mathrm{Ji}$ et al. 2010; Liu et al. 2015). Most of the fractures are nearly vertical (dips of $75^{\circ}-90^{\circ}$ ), with some high-angle fractures and few low-angle fractures (Fig. 2). The timing of fracture development is closely related to the timing of fault development ( $\mathrm{Ji}$ et al. 2010; Liu et al. 2015). Core observations show that tensional fractures, shear fractures and tensional-shear fractures are well developed and that the proportion of each fracture type is different (Fig. 3). The Wubao movement, which occurred during the late stages of the deposition of the Funing Formation, was a period of strong fault activity and the main period of fracture development. The faults and fractures have consistent formation mechanisms, and the formation and distribution of fractures are closely related to the stress field that was present during fault formation, development and activity (Gudmundsson et al. 2010; Savage and Brodsky 2011).

\subsection{Fault-fracture similarity}

\subsubsection{Principle of the self-similarity calculation}

Rocks rupture in a self-similar manner (Barton and Zoback 1992; Aguilar-Hernández and Ramírez-Santiago 2010). Based on the orientations of fractures in cores, the strike distributions of the faults and fractures are similar in different regions of the Jinhu Sag (Fig. 4). The nearly northsouth-oriented tensile principal stress that was present during the late stages of the deposition of the Funing Formation controlled the fault activity. The tectonic fractures, faults and other fractures exhibit statistically 

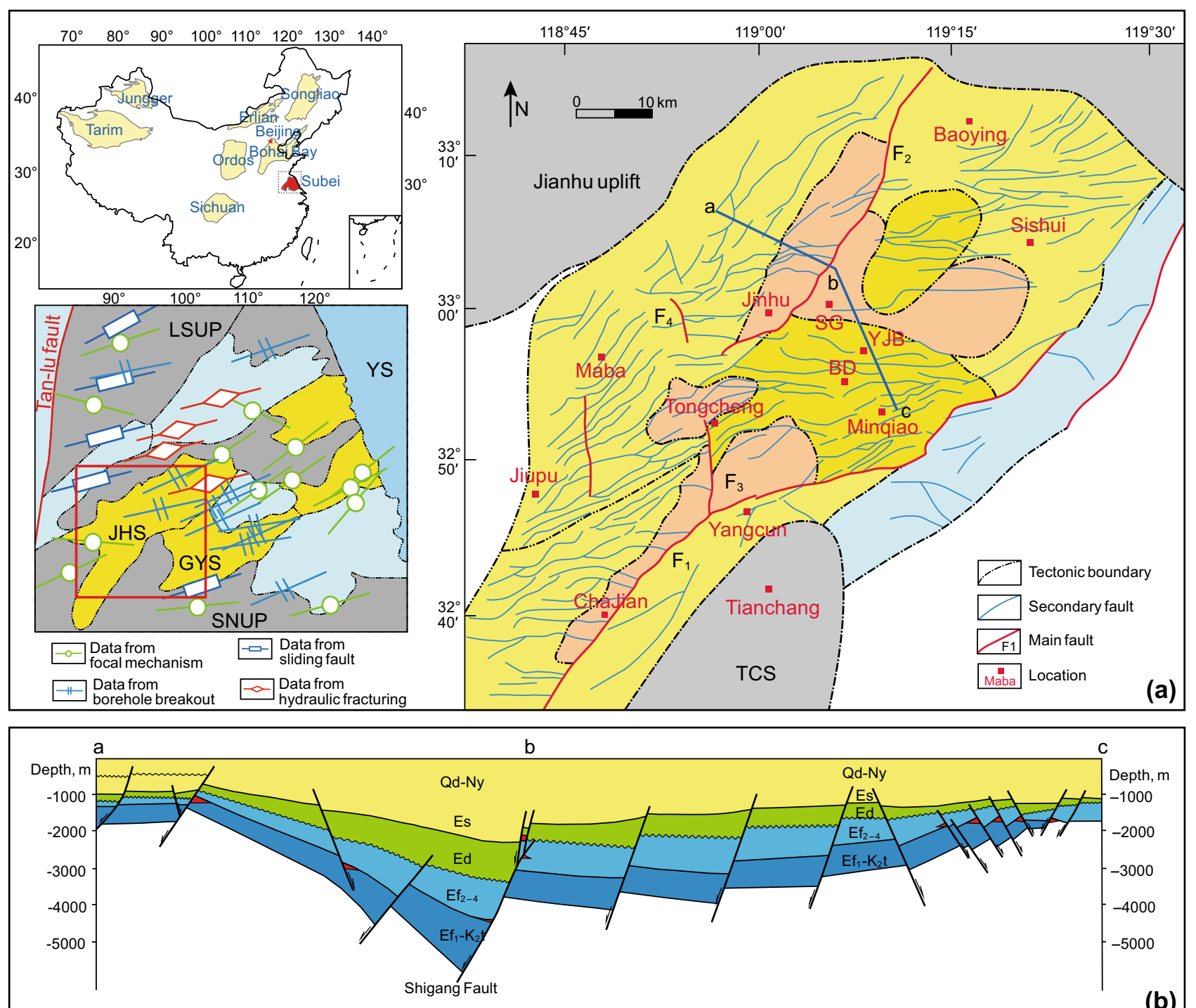

Fig. 1 a Location of the Jinhu Sag and the in situ stress orientation in the Subei Basin; the red box shows the study area. b Cross-section through the Jinhu Sag, with its location shown in Fig. 1a. The faults in Fig. $1 \mathrm{a}$ are normal faults. $F_{1}$ is the Yangcun fault; $F_{2}$ is the Shigang fault; $\mathrm{F}_{3}$ is the Tongcheng fault; and $\mathrm{F}_{4}$ is the Cuizhuang fault. $J H S$ Jinhu Sag, GYS Gaoyou Sag, YS Yellow Sea, LSUP Lusu Uplift, SNUP Sunan Uplift, TCS Tianchang Salient, $B D$ Biandong, YJB

significant self-similarity in terms of geometric morphology, tectonic evolution and genetic dynamics. The selfsimilarity of fractures is comprehensively quantified and characterized by the information dimension D. Closely related to the index of fault development, the fault $D$ value can be used as a comprehensive index of the fault number, scale, pattern, horizontal length and distribution heterogeneity and can be calculated as follows (Matsumoto et al. 1992; Davarpanah and Babaie 2013):
Yangjiaba and $S G$ Shigang. $\mathrm{K}_{2} t$ the Late Cretaceous Taizhou Formation; $\mathrm{E} f_{1}$ the first member of the Eocene Funing Formation; $\mathrm{E} f_{2-4}$ the second, third and fourth members of the Eocene Funing Formation; Ed the Eocene Dainan Formation; Es the Eocene Sanduo Formation; $\mathrm{N} y$ the Neogene Yancheng Formation; and $\mathrm{Q} d$ the Quaternary Dongtai Formation

$D=-\lim _{\varepsilon \rightarrow 0} \frac{I(\varepsilon)}{\ln (\varepsilon)}$

where $I(\varepsilon)=\sum_{i=1}^{N(\varepsilon)} P_{i} \ln \left(1 / P_{i}\right), P_{i}$ is the probability that each point falls in the $i$ th grid, and $\varepsilon$ is the length of the side of the grid (m). In this calculation, by changing unit length $(r)$ of the fractal statistics, we can obtain the information dimension if there is a linear relationship between $I(r)$ and $\ln r$, where $I(r)=\sum_{i=1}^{N(r)} P_{i}(r) \ln \left[1 / P_{i}(r)\right]$.

$I(r)=-D \ln (r)+C$ 


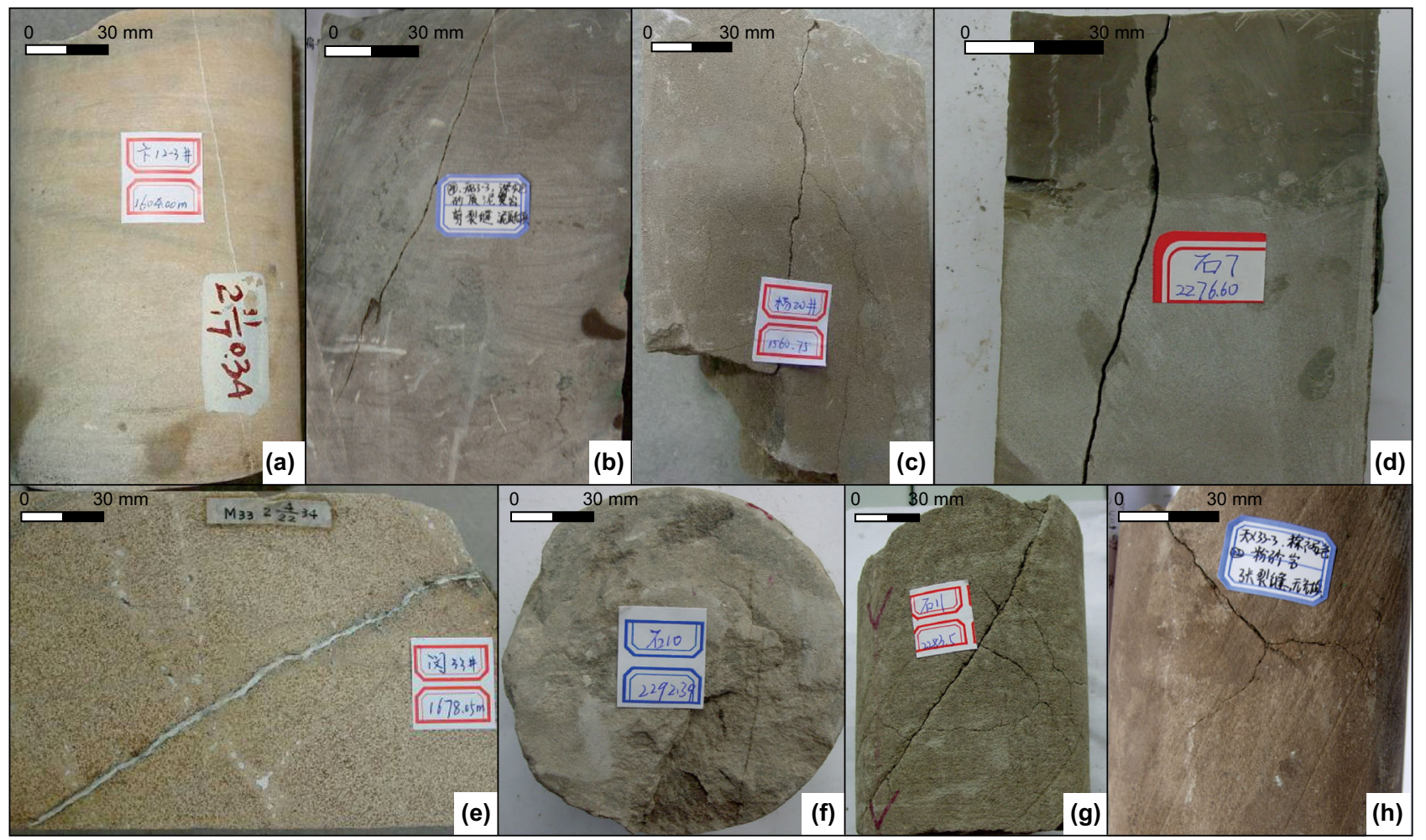

Fig. 2 Observations of core fractures from the Jinhu Sag. a Vertical fracture filled with calcite in the B12-3 well, $1604.00 \mathrm{~m}$. b High-angle tensile-shear fracture in the TX33-3 well, 2144.92 m. c High-angle tensile fractures in the Y20 well, $1560.75 \mathrm{~m}$. d Unfilled tensile-shear fracture in the S7 well, $2276.60 \mathrm{~m}$. e Low-angle shear fracture filled with calcite in the M33 well, $1678.05 \mathrm{~m}$. f High-angle parallel shear fractures in the S10 well, $2292.39 \mathrm{~m}$. $\mathrm{g}$ Tensile fractures that are well developed around a high-angle shear fracture in the S11 well, $2283.55 \mathrm{~m}$. h High-angle tensile fracture showing bifurcation at the end of the fracture in the TX33-3 well, $2071.11 \mathrm{~m}$
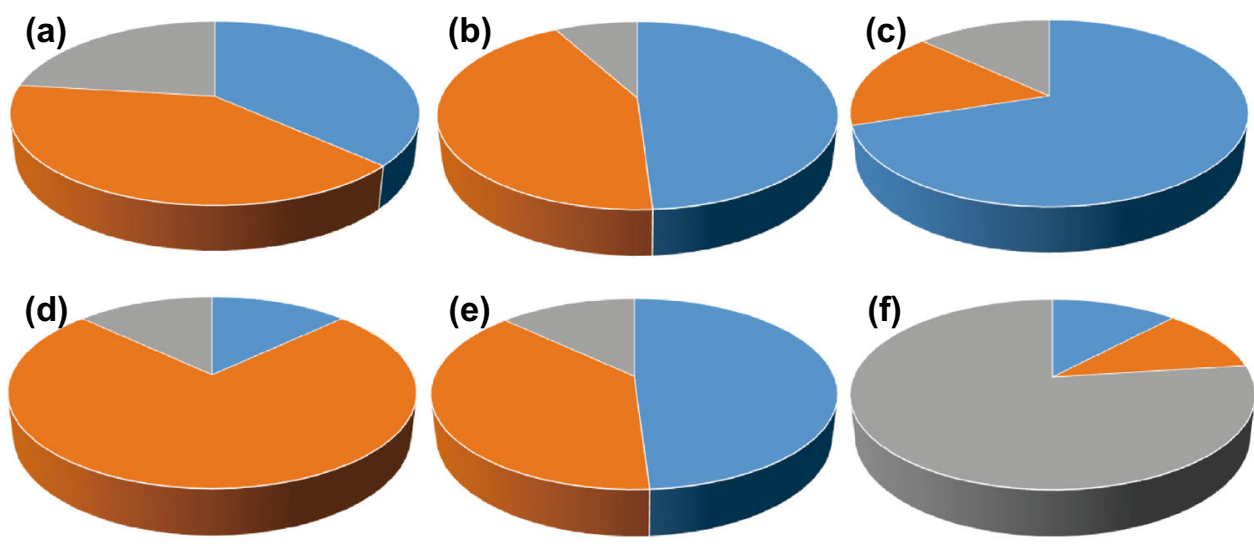

(e)

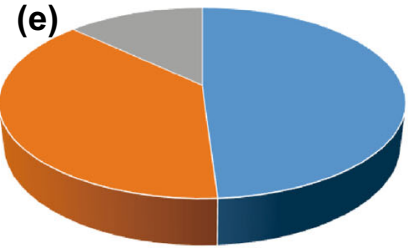

(f)

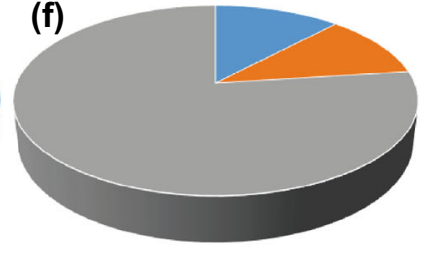

Tensile fracture

Shear fracture

Tensile-shear fracture

Fig. 3 Statistical results of tensile and shear fractures in different regions of the Jinhu Sag. a Biandong area. b Minqiao area. c Yangjiaba area. d Tongcheng area. e Shigang area. f Qiaohekou area. See Fig. 1a for locations

In Eq. (2), $r$ is the unit length of the fractal statistics (m); $D$ is the information dimension of the fracture (or fault); and $C$ is the fitting coefficient of fault similarity.

\subsubsection{Self-similarity evaluation of fractures in the Jinhu Sag}

Fault systems show self-organization (Shaw 2004; Feng et al. 2016). Early faults affect the subsequent development of new faults, and the pattern of later-forming faults reflects the distribution of earlier faults. Faults at different 

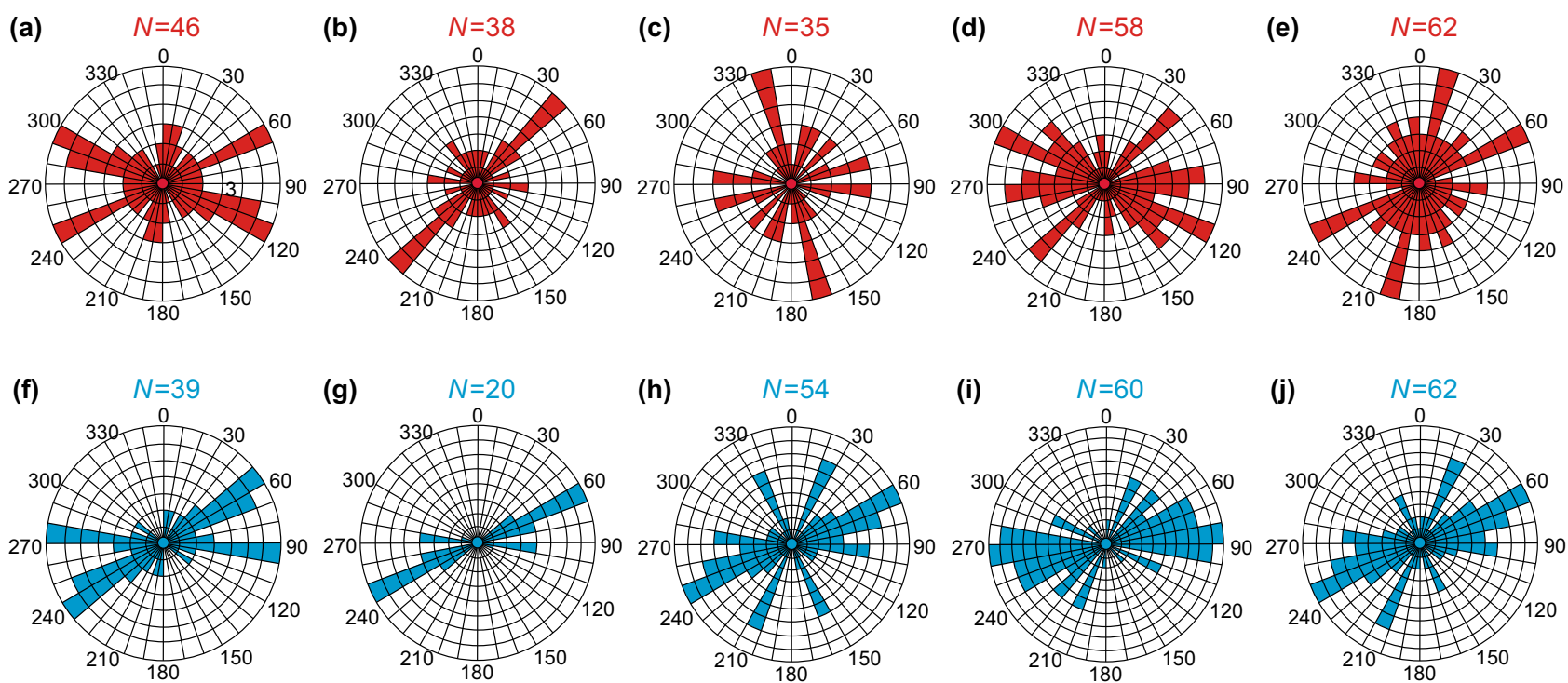

Fig. 4 Rose diagrams of strike orientations of fractures and faults in different regions of the Jinhu Sag. a Fracture strikes in the Tongcheng area. b Fracture strikes in the Shigang area. c Fracture strikes in the Qiaohekou area. d Fracture strikes in the Yangjiaba area. e Fracture strikes in the Minqiao area. f Fault strikes in the Tongcheng area. g Fault strikes in the Shigang area. h Fault strikes in the Qiaohekou area. i Fault strikes in the Yangjiaba area. j Fault strikes in the Minqiao area. See Fig. 1a for locations scales that develop during different time periods have a statistically significant similarity (Hirata 1989; Sarp 2014; Wang et al. 2018). In the Jinhu Sag, we statistically analyzed 826 faults at different scales, including the sagcontrolling large fault and associated secondary faults. The degree of similarity of fractures can be expressed by the fitting coefficient $R^{2}$ of Eq. (2) (Sarp 2014; Mirzaie et al. 2015). Using this principle, we developed a computer program to calculate the $D$ values of the lengths of faults (including the scale information of the faults) with different orientations and scales in the 10,838 statistical units $(r=8 \mathrm{~km})$ in the research area to derive the distribution of the $D$ and $R^{2}$ values for the faults in the Jinhu Sag (Fig. 5a). A high $D$ value usually indicates that the classification of fractures is complicated because the degree of development of fractures is high and a fracture network has formed (Hou 1994). In zones with high $D$ values, the fault blocks are complicated and fragmented, resulting in small and fragmented reservoirs. In the region of fault development, the $D$ values are in the range of 1.4-1.9, whereas at the edge of the sag, the $D$ values are less than 1.0. Generally, if $R^{2}>0.97$, the faults in a unit are considered statistically self-similar (Sarp 2014; Mirzaie et al. 2015). Of the 10,838 units, the $R^{2}$ values for the $D$ values are $>0.97$ for 9169 $(84.6 \%)$ statistical units, $>0.99$ for $7641(70.5 \%)$ statistical units, and $<0.90$ for only $596(5.5 \%)$ statistical units (Fig. 5b). These results indicate that the faults in the Jinhu Sag, which have different orientations and scales and formed during different time periods, are statistically selfsimilar.
Studies have shown that due to the influence of higherorder faults, lower-order faults always develop with orientations that exhibit a high degree of similarity to those of the higher-order faults, which is the theoretical basis for predicting fractures of different scales. As shown in Fig. 6, we selected 390 higher-order faults as the framework model and simulated the development of 436 lower-order faults. The results indicate that the lower-order faults generally develop with an orientation that exhibits a high degree of similarity to that of the higher-order faults $\left(R^{2}\right.$ is high) and that the formation, development and distribution of secondary faults are closely related to the distribution of the higher-order faults.

\subsection{Calculation of fractures with different scales}

In a statistical unit, fractures nearly always develop at an orientation with a high similarity to that of the fault, and the $R^{2}$ values between fractures at different scales and the faults in the unit are high. Based on this principle, as shown in Fig. 7, we use Eqs. (1)-(2) to fit and derive the $D$ value (1.6619) and $R^{2}$ value (0.9991) of the faults in the statistical range of the fractal analysis in a certain unit. The ideal distribution of fractures at the scale of the cores should cause the $R^{2}$ value to further increase in the unit; namely, the ideal distribution approaches points A and B in Fig. 7. By changing the length of the grid side, $\varepsilon$, we can determine the values of $I(\varepsilon)$ that correspond to fractures at different scales and obtain the probability that a fracture will fall in each small grid. Based on the statistics, we calculate 

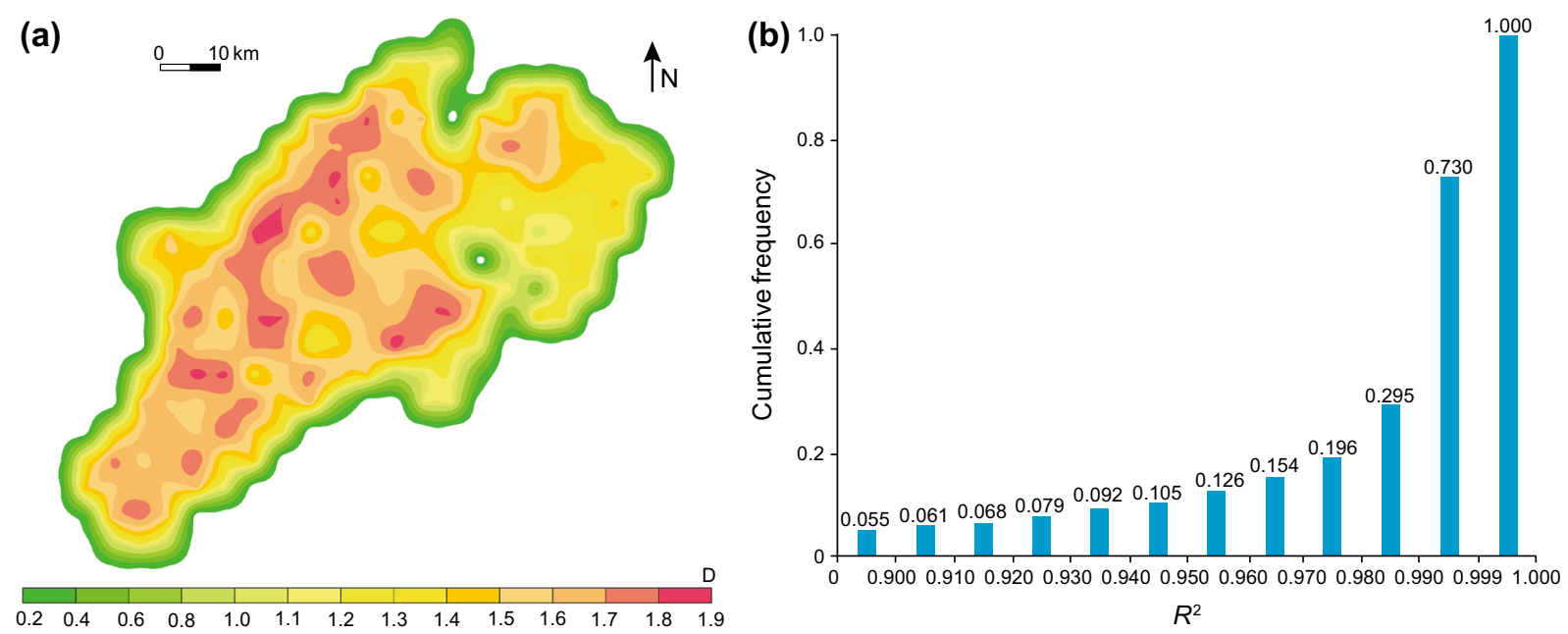

Fig. 5 a Distribution of fault information dimension $(D)$ in the Jinhu Sag and $\mathbf{b}$ cumulative frequency fitting coefficient $\left(R^{2}\right)$ of units in the Jinhu Sag

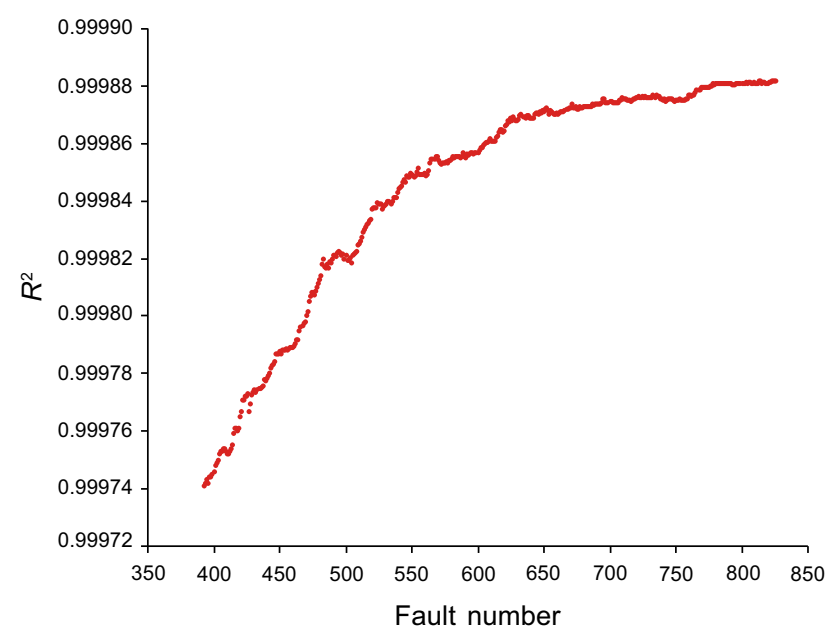

Fig. 6 Fault similarity evaluation of different directions and scales in the Jinhu Sag

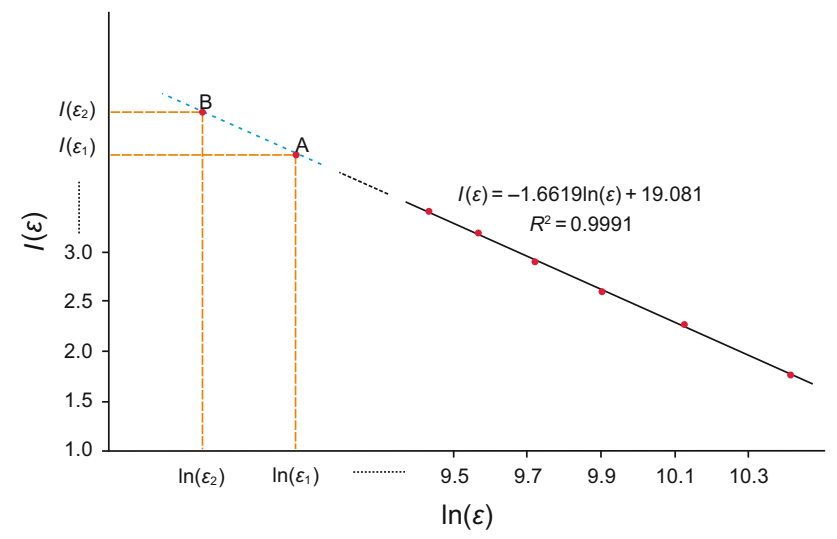

Fig. 7 Computational model of multiscale areal fracture density

the total length of the fractures with different scales in the unit and propose a model to calculate the areal densities of fractures with different scales: $\rho_{\mathrm{s}}=d \cdot \mathrm{e}^{-D \ln (d)+C}$

where $d$ is the scale of the fracture (m).

We use the principle for calculating the fracture $D$ value and compile the corresponding algorithm. After obtaining the data on the faults, we simulate the distribution of the areal fracture density. As shown in Fig. 8, the region with a dense distribution of secondary faults along the main fault is an area of high fracture density. We use the areal density of fractures at the thin-section scale (fracture scale $\left.d>10^{-5} \mathrm{~m}\right)$ to calculate the porosity; this parameter somewhat reflects the reservoir and corrosion capability of fractures. We use the linear density of fractures at the core scale (fracture scale $d>0.5 \mathrm{~m}$ ) to calculate the magnitude and direction of the permeability and use this parameter as a reference for the subsequent deployment of a well network. The areal fracture density at the thin-section scale is 4-12 $\mathrm{m} / \mathrm{m}^{2}$, and the areal fracture density at the core scale is $0.25-0.70 \mathrm{~m} / \mathrm{m}^{2}$.

\section{Prediction of the current apertures of fractures}

\subsection{Model for the distribution of fracture apertures}

The apertures of fractures statistically follow a skewed distribution (Nelson 2001), and the median, mode and mean of the apertures are commonly different. In a unit, a few fractures with large apertures can dominate the fracture permeability direction. The length of a fracture is positively correlated with the aperture of the fracture (Nelson 2001). We assign different apertures to the areal densities of fractures at different scales that were calculated in the 

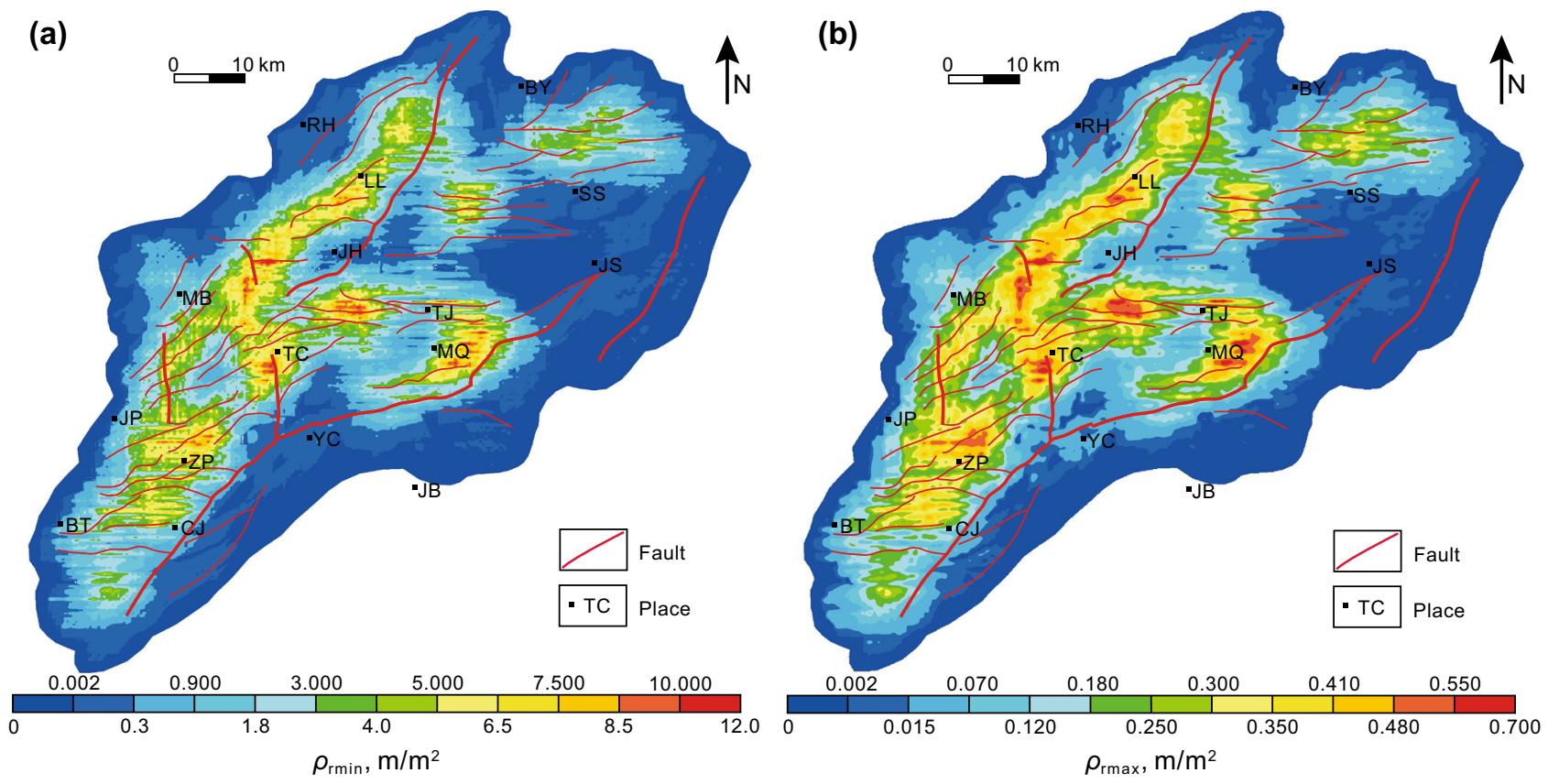

Fig. 8 Distribution of multiscale areal fracture density. a Thin-section scale $\left(d>10^{-5} \mathrm{~m}\right)$ and $\mathbf{b}$ core scale $(d>0.5 \mathrm{~m}) . \rho_{\text {rmin }}$ is the areal fracture density at the thin-section scale $\left(\mathrm{m} / \mathrm{m}^{2}\right)$, and $\rho_{\text {rmax }}$ is the areal fracture density at the core scale $\left(\mathrm{m} / \mathrm{m}^{2}\right)$

previous section to develop a skewed distribution model of fracture apertures at different scales and orientations in the unit.

The statistical analysis of the scales and apertures of more than 800 faults in the Jinhu Sag (Fig. 9) indicate that both exhibit strongly skewed distributions. By establishing a skewed distribution model, we assign different apertures to fractures at different scales. We then use the program to perform probability coupling between the apertures of the fractures in the cores and thin sections. The detailed scheme is as follows: Using the statistical analysis of the scales of the faults in the unit, we apply Fig. $9 \mathrm{~b}$ to determine the probability distribution of the scales of the fault and use the aperture model in Fig. 9a to obtain the average aperture of the fractures in each statistical unit, $b_{\text {aver }}$. We then use Eq. (3) to determine the areal density of fractures with various scales in the Jinhu Sag (the total length). The length distributions of all the statistical units are normalized according to Fig. 9b. Through cyclic iteration, we divide the total length of the fractures in each unit into $m$ segments. The length distribution is consistent with the skewed distribution model of the distribution. We assign the probability function of the apertures of fractures in the cores and thin sections into $m$ segments of fractures with different scales. The large-scale fractures have large apertures, and the small-scale fractures have small apertures, which simultaneously satisfy the following equation:

$b_{\text {aver }}=\frac{\sum_{i=1}^{m} b_{i} l_{i}}{\sum_{i=1}^{m} l_{i}}$ where $l_{i}$ is the length of the $i$ th segment of the fracture $(\mathrm{m})$; $b_{i}$ is the aperture of the $i$ th segment of the fracture (m); and $m$ is the number of segments of the fracture. If $m$ is sufficiently large, it is statistically significant. In this paper, the value of $m$ is 8260 .

Because of the probability coupling between fracture length and aperture, the fracture apertures in each unit are consistent with a skewed distribution, and the distribution of fracture apertures in the entire study area is also consistent with the frequency distribution shown in Fig. 9a.

\subsection{Aperture properties of fractures analyzed by simulations of the stress field}

\subsubsection{Numerical simulation of the in situ stress}

The fracture density is related to the paleostress field and fault activity, and the size and direction of the present horizontal principal stress determine the opening and permeability of unfilled fractures. Underground natural fractures have very small apertures, and they are very difficult to measure. The in situ stress field is the key to predicting the apertures of underground fractures, and the finite element method (FEM) has produced good results in the simulation of the in situ stress field (Jiu et al. 2013b; Liu et al. 2017b, 2018b; Zhao and Hou 2017). The FEM requires an established geological model, a mechanical model and a mathematical model (Jiu et al. 2013b; Liu et al. 2017b, 2018b). We developed a geological model 

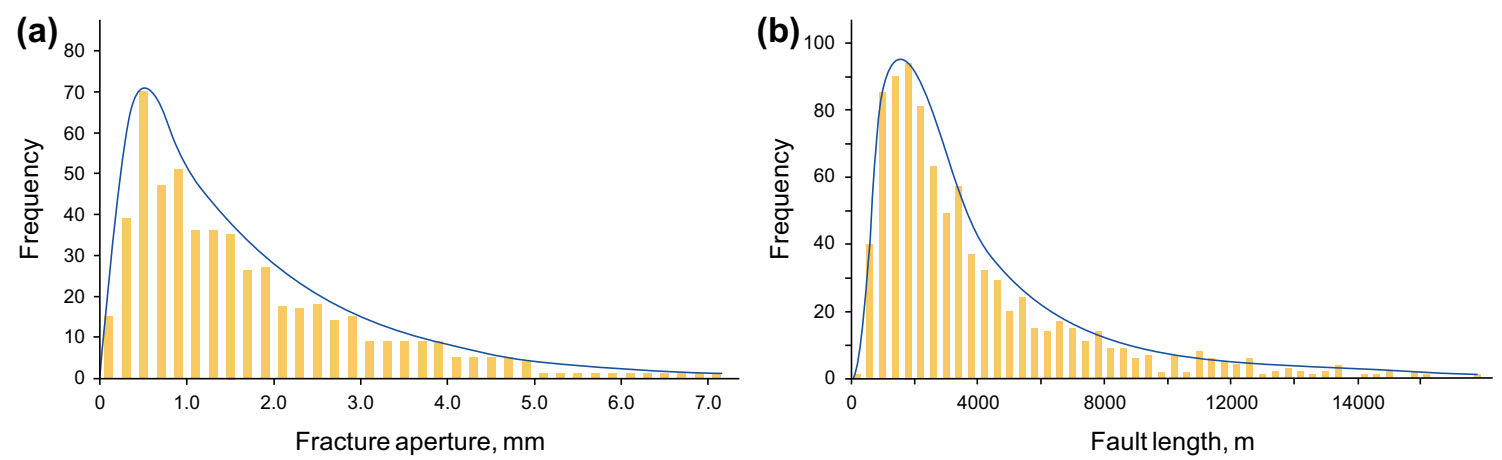

Fig. 9 a Skewed distribution model of fracture apertures and $\mathbf{b}$ skewed distribution model of fault lengths

based on a three-dimensional structure map of the second member of the Funing Formation, and triaxial fracturing experiments performed on rocks from the Biandong, Minqiao, Tongcheng and Shigang regions are used to determine the mechanical parameters of the rock formations. These include the Poisson's ratio, elastic modulus, uniaxial compressive-shear strength and internal frictional angle. The results are combined to develop a mechanical model of the Jinhu Sag. Because of the mechanical, physical and mathematical principles used in the FEM simulation, the geological model was meshed with triangular elements and subdivided into a series of nodes and elements. The fault zone and target stratum were meshed with a fine grid, and the surrounding rocks were meshed with a coarse grid. The model was subdivided into 304,125 elements and contained 66,566 nodes, and each element and node was endowed with different mechanical attributes.

In this study, based on data from earthquake focal mechanisms, hydraulic fracturing, borehole breakouts and experiments on the sound velocity of oriented cores (Figs. 1a, 10, Table 1), the direction of the maximum horizontal principal compressive stress $\left(\sigma_{\mathrm{H}}\right)$ was determined. The boundary conditions in the stress simulation included the stress direction, stress magnitude and displacement constraints determined via the FEM. Hydraulic fracturing and the acoustic emission (AE) method are used to estimate the magnitude of the in situ stress (Healy and Zoback 1988; Seto et al. 1997; Jie et al. 2005). When a core is removed from the ground, due to differences in the threedirection principal stresses in the core, the core will develop microcracks that are positively correlated with the stress. The in situ stress can be analyzed based on loading data. In the Jinhu Sag, the values of $\sigma_{\mathrm{H}}$ and $\sigma_{\mathrm{h}}$ calculated by the AE method for the depth range of 1600-2000 m were 30.1-44.4 MPa and 25.7-30.4 MPa, respectively (Fig. 10e, f). Based on hydraulic fracturing (Table 1) and the AE method (Fig. 10e, f), compressive stresses of 38 and $28 \mathrm{MPa}$ were applied to the ENE and NNW boundaries of the model, respectively. After debugging the above approach, the appropriate displacement was applied to the geological model to prevent it from undergoing rotation and rigid displacement and to facilitate the simulation. The Y-direction constraint was applied to the SSW boundary of the model, the X-direction constraint was applied to the WSW boundary, and the Z-direction constraint was applied to the bottom boundary. The distributions of the maximum, intermediate and minimum principal stresses were determined using a 3D FEM numerical simulation (Fig. 11).

\subsubsection{Apertures of underground fractures}

In general, the current stress field no longer generates new fractures, and the linear density and occurrence of fractures essentially remain unchanged. However, under the influence of three-dimensional compressive stress, fractures can partially close, decreasing the seepage capability. WillisRichards et al. (1996) and Jing et al. (1998) considered the influences of normal stress and shear stress on the aperture of a fracture and derived an equation to calculate the aperture of a fracture within the in situ stress field as follows:

$b=\frac{b_{0}}{1+9 \sigma_{\mathrm{n}}^{\prime} / \sigma_{\text {nref }}}+b_{\text {res }}$

where $b_{0}$ and $b$ are the original and current aperture of the fracture (m), respectively; $\sigma_{\mathrm{n}}^{\prime}$ is the effective normal stress $(\mathrm{MPa}) ; b_{\text {res }}$ is the residual aperture of the fracture (m); and $\sigma_{\text {nref }}$ is the corresponding effective normal stress (MPa) when the fracture aperture decreases by $90 \%$ (unit: MPa) and is a coefficient related to lithology. Some researchers (Durham and Bonner 1994; Willis-Richards et al. 1996) have provided test values for different conditions. The results from Durham and Bonner (1994) show higher values of $\sigma_{\text {nref }}$ that can exceed $200 \mathrm{MPa}$, whereas the results from Willis-Richards et al. (1996) show that the value of $\sigma_{\text {nref }}$ is a constant between 10 and $26 \mathrm{MPa}$. Qin (2002) tested the permeability of low-permeability sandstone in eastern China and found that, for samples with a uniaxial 

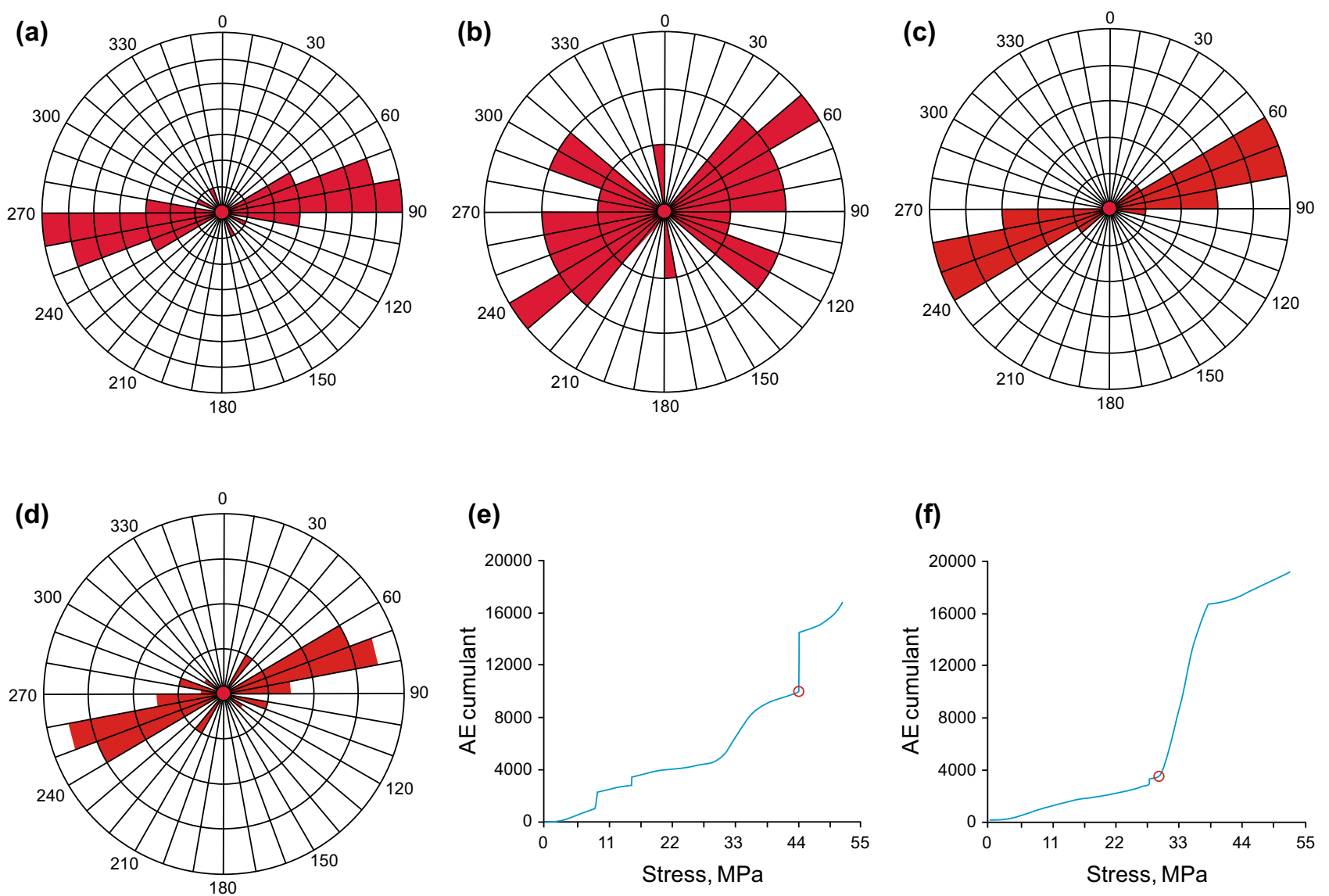

Fig. 10 The direction of the present maximum horizontal principal stress within the Jinhu Sag. a Derived from hydraulic fracturing $(N=18)$. b Derived from sound velocity experiments in oriented cores $(N=42)$. c Derived from borehole breakouts in the Subei Basin $(N=15)$. d Derived from focal mechanisms and sliding faults in the
Subei Basin $(N=22)$. Curves of in situ stress measurements based on the initial pressures of acoustic emissions for samples in the Shigang area $(1921.11 \mathrm{~m})$ : e vertical direction and $\mathbf{f}$ horizontal direction. See Fig. 1a for locations
Table 1 The size and direction of in situ stresses derived from hydraulic fracturing in the Jinhu Sag

\begin{tabular}{|c|c|c|c|c|c|}
\hline & Biandong & Tongcheng & Shigang & Minqiao & Yangjiaba \\
\hline Depth, m & 1600 & 2600 & 2440 & 1580 & 1600 \\
\hline$\sigma_{\mathrm{H}}, \mathrm{MPa}$ & 38.0 & 37.0 & 37.0 & 38.0 & 38.1 \\
\hline$\sigma_{\mathrm{h}}, \mathrm{MPa}$ & 28.0 & 32.0 & 32.0 & 28.0 & 27.7 \\
\hline Direction of $\sigma_{\mathrm{H}}$ & W-E $90.0^{\circ}$ & ENE $79.0^{\circ}$ & ENE $57.5^{\circ}$ & ENE $86.0^{\circ}$ & ENE $87.0^{\circ}$ \\
\hline Direction of $\sigma_{\mathrm{h}}$ & $\mathrm{N}-\mathrm{S} 0.0^{\circ}$ & NNW $349.0^{\circ}$ & NNW $327.5^{\circ}$ & SSE $176.0^{\circ}$ & SSE $177.0^{\circ}$ \\
\hline
\end{tabular}

compression strength of 30-50 MPa, $\sigma_{\text {nref }}$ should be considered to be $30 \mathrm{MPa}$. In addition, $\sigma_{\mathrm{n}}^{\prime}$ in Eq. (5) is the effective normal stress, which can be determined by stress simulation, and $b_{0}$ can be determined by the distribution of fracture apertures in Fig. 9a and Eq. (4).

Using Eq. (5), we can calculate the apertures and the means of underground fractures that have different scales. Figure 12 shows the distribution of the average fracture apertures. Due to the influence of the fractures, the in situ stress and the initial aperture (scale) of the fractures, the distribution of the fracture apertures is discontinuous and has large local variations. At the edge of the sag, the fracture apertures are large, whereas in the center of the sag, the fracture apertures are small. The fracture apertures are concentrated in the range of $(6-20) \times 10^{-5} \mathrm{~m}$.

\section{Model for calculating the porosity and permeability of fractures at different scales}

In the individual statistical units, fractures at different scales have different flow capacities, and long fractures with large apertures usually play dominant roles in fluid 

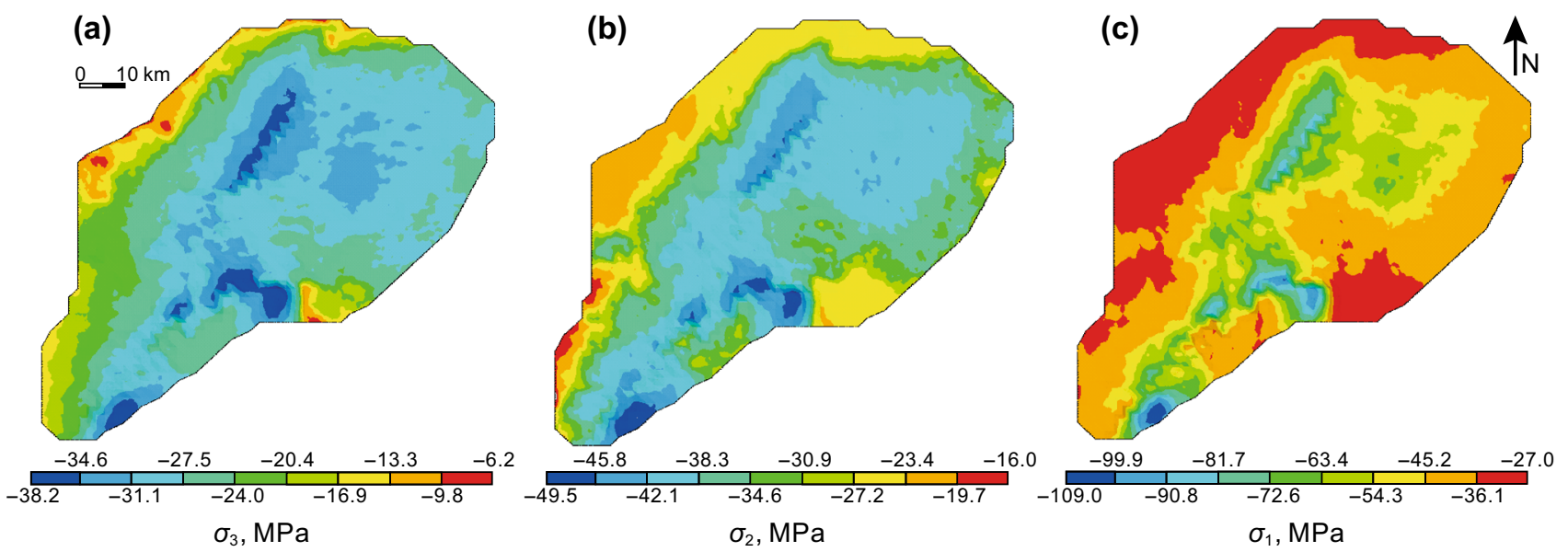

Fig. 11 Distributions of in situ stresses in the Jinhu Sag. a Minimum principal stress. b Intermediate principal stress. c Maximum principal stress (Negative values represent compressive stress)

flow. The flow capacities of fractures at different scales can be evaluated using an appropriate model. By developing a model of the micro-unit, we can calculate the porosity and permeability of the fracture. As shown in Fig. 13, we use the fracture as the reference object to establish a static coordinate system (O-ENWS), and the geodetic coordinates of the reference object are used to establish a dynamic coordinate system $(\mathrm{O}-\mathrm{XY})$. We define $\theta$ as the angle between the $\mathrm{OX}$ axis in the horizontal plane and true east, and this term represents the rotation angle of the dynamic coordinate system. By adjusting the value of $\theta$, we can calculate the permeabilities of fractures in various orientations in the dynamic coordinate system. We define $\theta$ as negative when the OX axis is oriented toward the

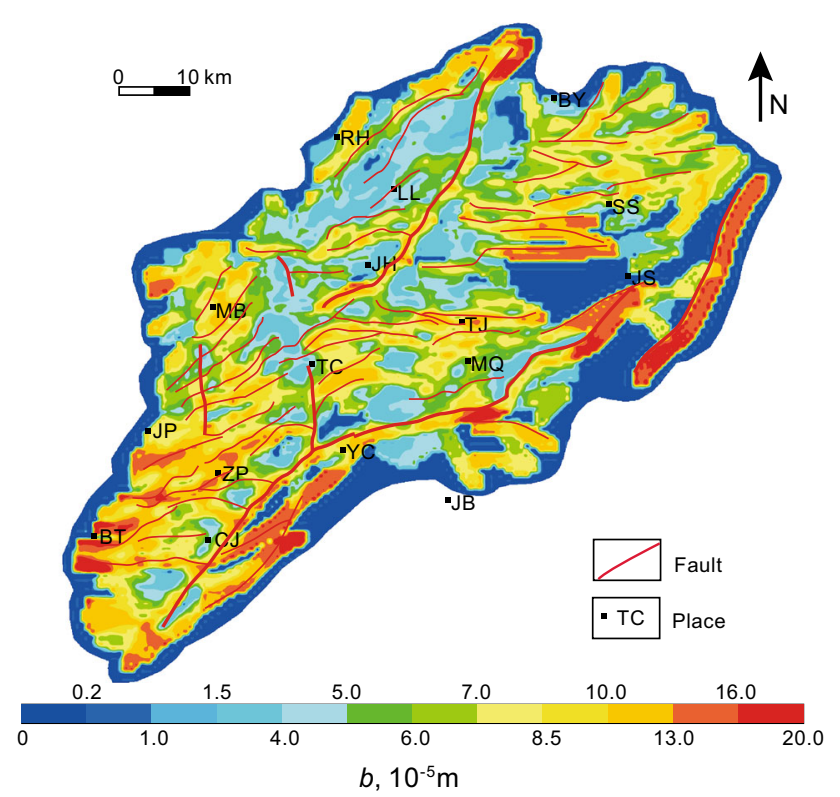

Fig. 12 Distribution of average fracture apertures in the second member of the Funing Formation northeast and as positive when it is oriented toward the southeast. We use this model to evaluate the flow capacities of fractures at different scales.

The calculation of the fracture porosity in this paper does not consider corrosion of the fracture surface. Using the calculation model for the parameters of multiscale and multiperiod fractures in Fig. 13, we derive the corresponding algorithm and obtain the formula to calculate the porosity of a fracture $\varphi$ :

$\varphi=\frac{\rho_{\mathrm{rmin}} \cdot R^{2}}{\sum_{i=1}^{m} l_{i}} \cdot \sum_{i=1}^{m}\left(b_{i} \cdot l_{i}\right) \times 100 \%$

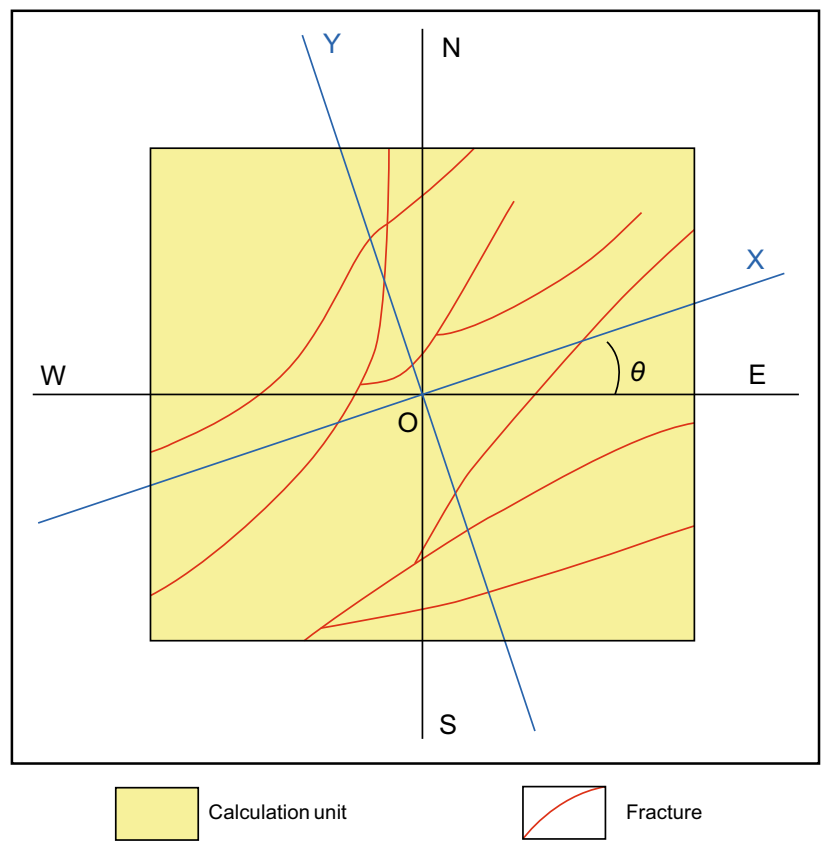

Fig. 13 Calculation model of fracture porosity and permeability 
In complicated geological conditions, fractures in reservoirs are affected by multiple episodes of tectonic activity, and the occurrence, areal density and aperture values are often different in each group of fractures. Different parts of a single fracture can also have different apertures. When multiple fractures are present in a unit, the equation to calculate the direction of maximum permeability, $\theta_{\max }$, is as follows:

$\theta_{\max }=\arctan \left(\frac{\sum_{j=1}^{n} \sum_{i=1}^{m} b_{j i}^{3} l_{j i} n_{\mathrm{x} j}}{\sum_{j=1}^{n} \sum_{i=1}^{m} b_{j i}^{3} l_{j i} n_{\mathrm{y} j}}\right)$

The maximum permeability of the fracture, $K_{\max }$, can be expressed as follows: fracture porosity does not consider corrosion/dissolution on the fracture surfaces. Compared with the aperture statistics of Nelson (2001), Anders et al. (2014) and Zeng et al. (2013), the prediction results in Fig. 14 are relatively low. The fracture porosity is closely related to the areal density (Fig. 8a) and the region with high porosities of $(35-95) \times 10^{-3} \%$. The fracture porosity is high in the region of secondary faults near the main faults. Along the edge of the sag, the fracture porosity is low in the region of weakly developed secondary faults and areas of low structure.

$K_{\max }=\sum_{j=1}^{n} \sum_{i=1}^{m}\left[\frac{b_{j i}^{3} l_{j i}}{12} \cdot \frac{\left(n_{x j} \sin \theta_{\max }+n_{y j} \cos \theta_{\max }\right)^{2}+n_{z j}^{2}\left(n_{x j} \cos \theta_{\max }-n_{y j} \sin \theta_{\max }\right)^{2}}{\sqrt{n_{x j}^{2}+n_{y j}^{2}}}\right] \cdot \frac{\rho_{\mathrm{rmax}} \cdot R}{\sum_{i=1}^{m} l_{i}}$

In Eqs. (6)-(8), $R$ is the length of the side of the unit (m); $\rho_{\text {rmin }}$ is the areal density of fractures at the thin-section scale $\left(\mathrm{m} / \mathrm{m}^{2}\right) ; \rho_{\text {rmax }}$ is the linear density of fractures at the core scale $\left(\mathrm{m} / \mathrm{m}^{2}\right) ; n$ is the number of fractures; and $n_{x j}$ and $n_{y j}$ are the components of the unit normal vector of the $j$ th group of fracture planes along the $\mathrm{X}$ - and Y-axes, respectively.

\section{Distributions of fracture porosity and permeability}

\subsection{Distribution of fracture porosity}

Based on Eqs. (1)-(8), we use programs written in Visual $\mathrm{C}++6.0$ to develop the Quantitative Prediction of Multiscale Fractures (QPMF) system and to perform a quantitative evaluation of the development model with the fracture parameters from the oil- and gas-bearing areas. The algorithm parameters used in this system are as follows: The unit length of the fractal statistics $(r)$ in the Jinhu Sag was $8000 \mathrm{~m}$; the fracture lengths used in the areal density of fractures at the thin-section scale and core scale were $5 \times 10^{-5}$ and $0.5 \mathrm{~m}$, respectively; the length of the side of the unit $(R)$ was $10,000 \mathrm{~m}$; the areal fracture density at different scales and fracture opening used for calculation are shown in Figs. 8 and 9a. We adopt the areal density of fractures at the thin-section scale to calculate the distribution of fracture porosity (Fig. 14). The calculated

\subsection{Distribution of fracture permeability}

As shown in Figs. 15 and 16, the fracture permeability of the reservoirs in the second member of the Funing Formation is as high as (20-120) $\times 10^{-3} \mu^{2}$. Few secondary fractures are located near the large faults, but they have

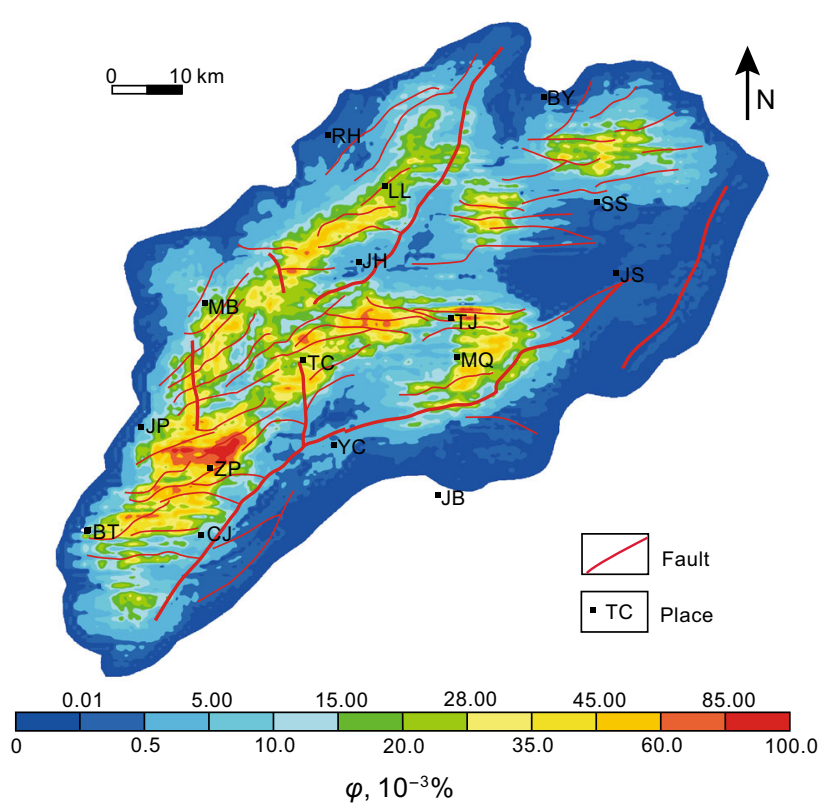

Fig. 14 Distribution of fracture porosity in the second member of the Funing Formation 


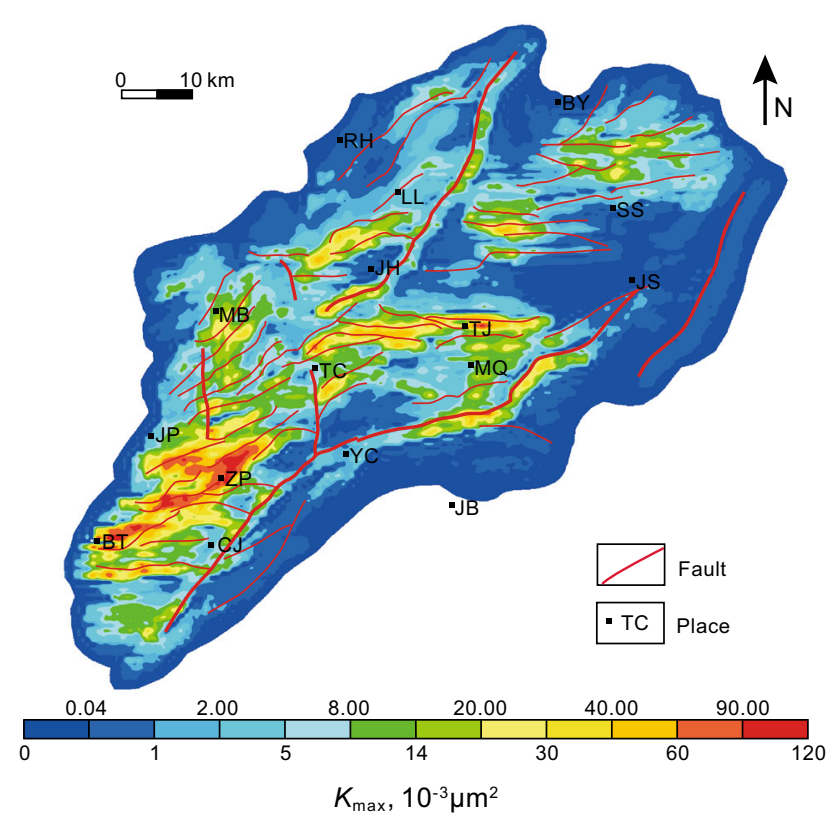

Fig. 15 Distribution of fracture permeability in the second member of the Funing Formation

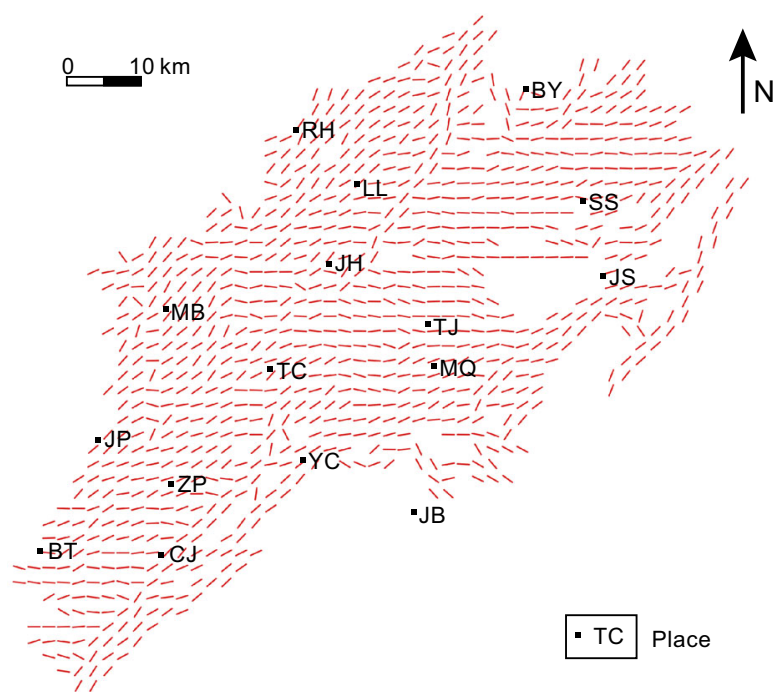

Fig. 16 Orientation distribution of maximum fracture permeability in the second member of the Funing Formation

large apertures and strong flow capacities. Therefore, this type of fault usually plays a role in determining the main permeability directions of the fractures (Fig. 16). The paleostress field that affected the formation and activity of faults (fractures) is important for controlling the direction of primary permeability, and the current maximum horizontal principal stress (ENE) plays a role in changing the main seepage direction. The fractures that trend NE-ESE $\left(45^{\circ}-120^{\circ}\right)$ are relatively open. Thus, in each unit, the flow capacities of the fractures with these orientations are stronger, so the main direction of fracture permeability generally converges toward the ENE.

\section{Results and discussion}

\subsection{Comparative validation of simulation results}

A comparison between the linear density and porosity of fractures in the cores and the predicted results shows that the consistency is relatively good in the Tongcheng, Shigang, Qiaohekou, Yangjiaba and Minqiao regions but not in the Biandong region where the prediction has a relatively large error. This error may be related to the reservoirs in the second member of the Funing Formation, which in this area includes mixed deposits of lacustrine limestone and sandstone. Compared to low-permeability sandstone, these rocks are more brittle and prone to fracture. Therefore, the areal fracture density in the observed core is much higher than in the predicted results. The simulation results generally reflect the differences and variations in the fracture parameters in different regions fairly well (Table 2).

\subsection{Development patterns of fractures in the Jinhu Sag}

Previous studies (Ji et al. 2010; Liu et al. 2015) have used fine-scale geological models for multiparameter simulations of fractures, and the results indicate that the areal density and aperture are different for fractures in different regions. Fractures in the Minqiao and Yangiiaba regions have large apertures and exhibit a high density, whereas fractures in the Shigang area have small apertures and exhibit a relatively high density. Fractures in the Qiaohekou area exhibit a low density and relatively large apertures and are typically low-porosity and high-permeability fractures. Fractures are moderately developed in the Tongcheng area. Therefore, using the relationships between the areal densities and apertures of the fractures in the different statistical units in these regions, we combine the distributions of the fracture porosity and permeability to develop classification criteria for the patterns of fracture development (Table 3 ). We preliminarily divide the fractures in the Jinhu Sag into five types (Figs. 17 and 18):

1. Low-porosity and low-permeability fractures have low porosity and permeability values and are mainly located in Yangcun, Jinhu, and along the edge of the sag. The sand bodies in these regions are thin and have poor lateral continuity, high clay contents and low degrees of brittleness. These fractures are mainly present in areas where faults are poorly developed. The 
Table 2 Correlation between numerical simulations and core measurements in the Jinhu Sag
Table 3 Classification criteria for different fracture development patterns in the Jinhu Sag

\begin{tabular}{|c|c|c|c|c|c|c|}
\hline & Shigang & Qiaohekou & Yangjiaba & Tongcheng & Biandong & Minqiao \\
\hline \multicolumn{7}{|c|}{ Areal fracture density, $\mathrm{m} / \mathrm{m}^{2}$} \\
\hline Core observation & 0.212 & 0.024 & 0.0947 & 0.064 & 0.278 & 0.274 \\
\hline Simulation results & 0.223 & 0.027 & 0.0880 & 0.066 & 0.112 & 0.311 \\
\hline \multicolumn{7}{|c|}{ Fracture porosity, $10^{-3} \%$} \\
\hline Core observation & 22.8 & 0.8 & 14.7 & 1.5 & 37.4 & 33.2 \\
\hline Simulation results & 20.1 & 1.2 & 16.0 & 2.4 & 9.0 & 50.0 \\
\hline
\end{tabular}

\begin{tabular}{llll}
\hline Fracture type & $b / \rho$ & $\varphi \times K_{\max }$ & $K_{\max } / \varphi$ \\
\hline Low-porosity and low-permeability & - & $<1$ & - \\
High-porosity and high-permeability & $0.4-5$ & $>250$ & $0.25-2.5$ \\
Low-porosity and high-permeability & $>4$ & $>5$ & $>0.5$ \\
High-porosity and low-permeability & $<7$ & $>2$ & $<0.25$ \\
Transitional & Other areas of fracture development &
\end{tabular}

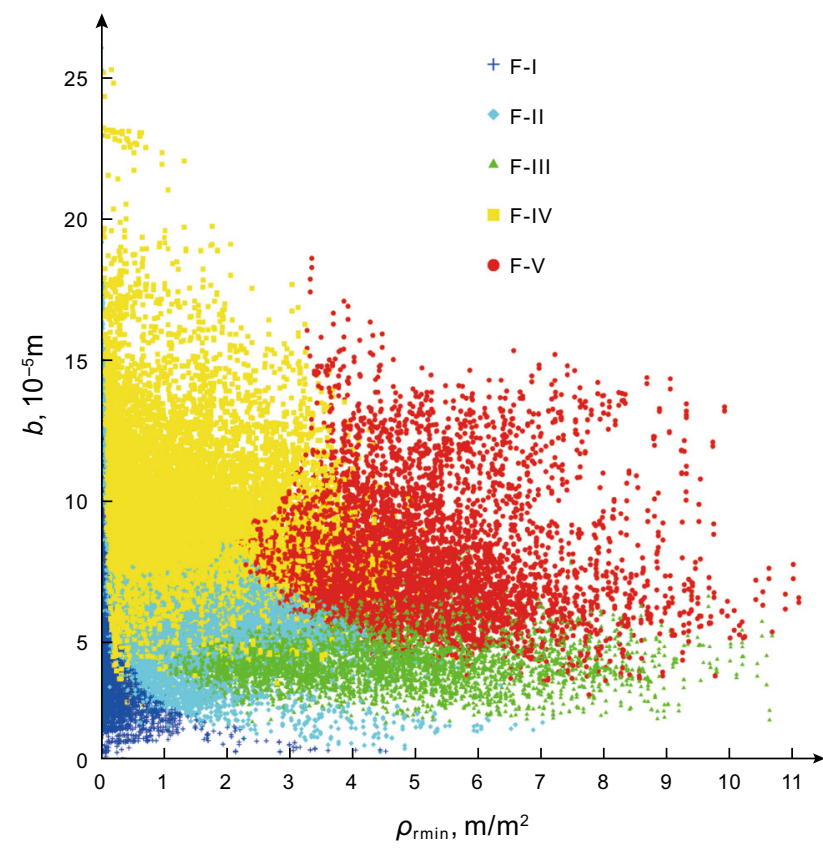

Fig. 17 Distribution of areal fracture density and aperture of different development patterns. F-I is the low-porosity and low-permeability fracture type; F-II is the transitional fracture type; F-III is the highporosity and low-permeability fracture type; F-IV is the low-porosity and high-permeability fracture type; and F-V is the high-porosity and high-permeability fracture type

faults are long but are low in density, and secondary faults are few.

2. High-porosity and high-permeability fractures have high porosity and permeability values and large apertures and are located in regions of high fracture density. The regions with these fractures experienced large differences in principal paleostresses and have a consistent fracture distribution. These fractures are

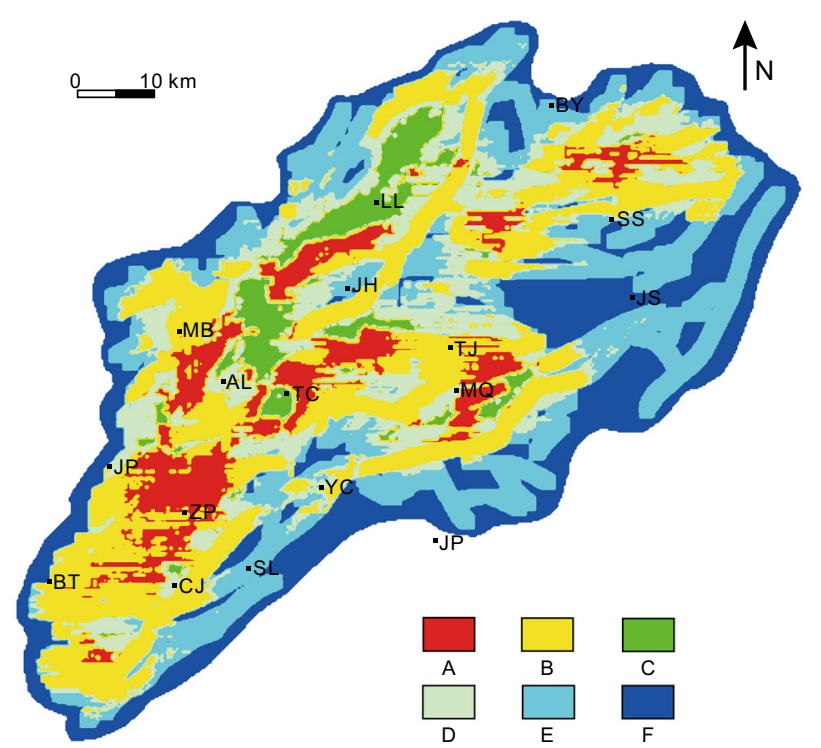

Fig. 18 Fracture development patterns in the second member of the Funing Formation in the Jinhu Sag. (A) High-porosity and highpermeability fractures. (B) Low-porosity and high-permeability fractures. (C) High-porosity and low-permeability fractures. (D) Transitional fractures. (E) Low-porosity and low-permeability fractures. (F) No fractures developed in the area

mainly distributed along the western slope and in the Minqiao area, and the current burial depth is moderate to relatively shallow $(1500-2600 \mathrm{~m})$. The reservoirs are mainly composed of very brittle siltstone and fine sandstone with low permeability and medium-sized pores that have a consistent distribution.

3. Low-porosity and high-permeability fractures have low porosity and high permeability values, relatively large fracture apertures and a low fracture density. They are located in regions of low paleostress due to 
fault activity, including near the Shigang fault, the Yangcun fault and some of the main faults. The fractures are mainly large, and their permeability is often dominated by a few fractures that have large apertures.

4. High-porosity and low-permeability fractures have high porosity and low permeability values, relatively small apertures and a high fracture density. They are located in regions of high paleostress release due to fault activity. The fractures are mainly small, densely distributed and located at moderate burial depths $(1900-2800 \mathrm{~m})$. They are mainly located in regions of high fracture density at the intersections of small secondary faults (e.g., Lvliang and north of Anle) and south of the Yangcun and Shigang faults.

5. Transitional fractures have moderate porosity and permeability values, and they are located in the transitional regions between the high-porosity and low-permeability fracture type and the low-porosity and high-permeability fracture type and in areas where the low-porosity and low-permeability fracture type transitions to other types of fractures. These fractures are mainly developed in the lower developmental zone of a fault, where secondary faults developed, but the scale is small, and the shapes of the faults are basically the same.

\section{Conclusions}

1. Fractures always develop in orientations similar to those of nearby faults, and this relationship can be used to predict the areal densities of fractures that have different scales. Furthermore, fracture apertures can be determined from observations of fractures in cores and thin sections. Fractures in reservoirs have scaling properties, and fractures at different scales have different effects on reservoir volume and fluid flow. We use the in situ stress field to calculate the apertures of underground fractures, to develop a predictive model for the porosity and permeability of multiperiod and multiscale fractures and to evaluate the flow capacities of fractures at different scales.

2. The minimum horizontal principal stress in the second member of the Funing Formation in the Jinhu Sag is 28-32 $\mathrm{MPa}$ and is oriented ENE to E-W $\left(75^{\circ}-90^{\circ}\right)$, and the maximum horizontal principal stress is $37-39 \mathrm{MPa}$ and is oriented NNW to $\mathrm{N}-\mathrm{S}\left(345^{\circ}-\right.$ $360^{\circ}$ ). The distribution of fracture apertures is discontinuous and shows significant local variation, with most of the fracture apertures in the range of $(6-20) \times 10^{-5} \mathrm{~m}$. The fracture porosity of the reservoirs in the second member of the Funing Formation is $(35-95) \times 10^{-3} \%$, and the permeability is $(20-120) \times 10^{-3} \mu \mathrm{m}^{2}$. The main fractures control the direction of the primary permeability, the paleostress played a role in controlling the direction of fracture-related seepage, and the in situ stress field has changed the main seepage direction of the fractures to the ENE.

3. The fracture density is related to the paleostress field and fault activity, and the opening and permeability of unfilled fractures are determined by the size and direction of the present horizontal principal stress. Controlled by the paleo- and modern stress field and the lithofacies, the porosity and permeability of the fractures vary among different areas in the Jinhu Sag. The fractures in the Jinhu Sag can be divided into the following five patterns: (1) low-porosity and lowpermeability fractures with small apertures and a low fracture density; (2) high-porosity and high-permeability fractures with large apertures and a high fracture density; (3) high-porosity and low-permeability fractures, which are mostly small-scale fractures with relatively small apertures and a relatively high density; (4) low-porosity and high-permeability fractures, which are mostly large-scale fractures with relatively large apertures and a relatively low fracture density; and (5) intermediate transitional fractures.

Acknowledgements This research was supported by the Fundamental Research Funds for the Central Universities (2652017308), the National Natural Science Foundation of China (Grant Nos. 41372139 and 41072098) and the National Science and Technology Major Project of China (2016ZX05046-003-001 and 2016ZX05034-004003). The authors would like to thank the staff of all the laboratories that cooperated in performing tests and analyses. We are also grateful to the five anonymous reviewers whose comments improved the quality of this manuscript.

Open Access This article is distributed under the terms of the Creative Commons Attribution 4.0 International License (http://creative commons.org/licenses/by/4.0/), which permits unrestricted use, distribution, and reproduction in any medium, provided you give appropriate credit to the original author(s) and the source, provide a link to the Creative Commons license, and indicate if changes were made.

\section{References}

Aguilar-Hernández A, Ramírez-Santiago G. Self-similar and selfaffine properties of two-dimensional fracture patterns in rocks. Math Geosci. 2010;42:925-54. https://doi.org/10.1007/s11004010-9279-4.

Anders MH, Laubach SE, Scholz CH. Microfractures: a review. J Struct Geol. 2014;69:377-94. https://doi.org/10.1016/j.jsg. 2014.05.011. 
Barton CA, Zoback MD. Self-similar distribution and properties of macroscopic fractures at depth in crystalline rock in the Cajon pass scientific drill hole. J Geophys Res. 1992;97:5181-200. https://doi.org/10.1029/91JB01674.

Brogi A. Variation in fracture patterns in damage zones related to strike-slip faults interfering with pre-existing fractures in sandstone (Calcione area, Southern Tuscany, Italy). J Struct Geol. 2011;33:644-61. https://doi.org/10.1016/j.jsg.2010.12.008.

Chen S-Q, Zeng L-B, Huang P, Sun S-H, Zhang W-L, Li X-Y. The application study on the multi-scales integrated prediction method to fractured reservoir description. Appl Geophys. 2016;13:80-92. https://doi.org/10.1007/s11770-016-0531-7.

Cook AE, Goldberg D, Kleinberg RL. Fracture-controlled gas hydrate systems in the northern Gulf of Mexico. Mar Pet Geol. 2008;25:932-41. https://doi.org/10.1016/j.marpetgeo.2008.01. 013.

Davarpanah A, Babaie HA. Anisotropy of fractal dimension of normal faults in northern Rocky Mountains: implications for the kinematics of Cenozoic extension and Yellowstone hotspot's thermal expansion. Tectonophysics. 2013;608:530-44. https:// doi.org/10.1016/j.tecto.2013.08.031.

Durham WB, Bonner BP. Self-propping and fluid flow in slightly offset joints at high effective pressures. J Geophys Res. 1994;99:9391-9. https://doi.org/10.1029/94JB00242.

Fan J, Qu X, Wang C, Lei Q, Cheng L, Yang Z. Natural fracture distribution and a new method predicting effective fractures in tight oil reservoirs in Ordos Basin, NW China. Pet Explor Dev. 2017;43:806-14.

Fang W, Jiang H, Li J, Wang Q, Killough J, Li L. A numerical simulation model for multi-scale flow in tight oil reservoirs. Pet Explor Dev. 2017;44:446-53.

Feng X, Jessell MW, Amponsah PO, Martin R, Ganne J, Liu D, Batt GE. Effect of strain-weakening on Oligocene-Miocene selforganization of the Australian-Pacific plate boundary fault in southern New Zealand: insights from numerical modelling. J Geodyn. 2016;100:130-43. https://doi.org/10.1016/j.jog.2016. 03.002 .

Gong J, Rossen WR. Modeling flow in naturally fractured reservoirs: effect of fracture aperture distribution on dominant sub-network for flow. Pet Sci. 2017;14:138-54. https://doi.org/10.1007/ s12182-016-0132-3.

Gudmundsson A, Simmenes TH, Larsen B, Philipp SL. Effects of internal structure and local stresses on fracture propagation, deflection, and arrest in fault zones. J Struct Geol. 2010;32:1643-55. https://doi.org/10.1016/j.jsg.2009.08.013.

Healy JH, Zoback MD. Hydraulic fracturing in situ stress measurements to $2.1 \mathrm{~km}$ depth at Cajon Pass, California. Geophys Res Lett. 1988;15:1005-8. https://doi.org/10.1029/ GL015i009p01005.

Hennings P, Allwardt P, Paul P, Zahm C, Reid R Jr, Alley H, Kirschner R, Lee B, Hough E. Relationship between fractures, fault zones, stress, and reservoir productivity in the Suban gas field, Sumatra, Indonesia. Am Assoc Pet Geol Bull. 2012;96:753-72. https://doi.org/10.1306/08161109084.

Hirata T. Fractal dimension of fault systems in Japan: fractal structure in rock fracture geometry at various scales. PAGEOPH. 1989;131:157-70. https://doi.org/10.1007/BF00874485.

Hou GT. Fractal analysis of fractures. J Basic Sci Eng. 1994;2:299-305

Ji Z-Z, Dai J-S, Wang B-F, Liu H-K. Multi-parameter quantitative calculation model for tectonic fracture. J China Univ Pet Ed Nat Sci. 2010;34:24-8.

Jie WL, Wu LP, Wen CJ, Chen DY. Determination of the present crustal stress state by using acoustic emission in the main borehole of the Chinese continental scientific drilling. Chin Geol. 2005;32:259-64.
Jing Z, Willis-Richards J, Watanabe K, Hashida T. A new 3D stochastic model for HDR geothermal reservoir in fractured crystalline rock. In: Proceedings of the 4th international HDR forum, Strasbourg; 1998.

Jiu K, Ding W, Huang W, You S, Zhang Y, Zeng W. Simulation of paleotectonic stress fields within Paleogene shale reservoirs and prediction of favorable zones for fracture development within the Zhanhua Depression, Bohai Bay Basin, East China. J Pet Sci Eng. 2013a;110:119-31. https://doi.org/10.1016/j.petrol.2013. 09.002.

Jiu K, Ding W, Huang W, Zhang Y, Zhao S, Hu L. Fractures of lacustrine shale reservoirs, the Zhanhua depression in the Bohai Bay Basin, Eastern China. Mar Pet Geol. 2013b;48:113-23. https://doi.org/10.1016/j.marpetgeo.2013.08.009.

Laubach SE, Olson JE, Gross MR. Mechanical and fracture stratigraphy. Am Assoc Pet Geol Bull. 2009;93:1413-26. https://doi. org/10.1306/07270909094

Liu C, Xie Q, Wang G, Zhang C, Wang L, Qi K. Reservoir properties and controlling factors of contact metamorphic zones of the diabase in the northern slope of the Gaoyou Sag, Subei Basin, Eastern China. J Nat Gas Sci Eng. 2016;35:392-411. https://doi. org/10.1016/j.jngse.2016.08.070.

Liu J, Dai J, Zou J, Yang H, Wang B, Zhou J. Quantitative prediction of permeability tensor of fractured reservoirs. Oil Gas Geol. 2015;36:1022-9.

Liu J, Ding W, Wang R, Yang H, Wang X, Li A. Methodology for quantitative prediction of fracture sealing with a case study of the Lower Cambrian Niutitang Formation in the Cen'gong block in South China. J Pet Sci Eng. 2018a;160:565-81. https://doi. org/10.1016/j.petrol.2017.10.046.

Liu J, Ding W, Wang R, Yin S, Yang H, Gu Y. Simulation of paleotectonic stress fields and quantitative prediction of multiperiod fractures in shale reservoirs: a case study of the Niutitang Formation in the Lower Cambrian in the Cen'gong block, South China. Mar Pet Geol. 2017a;84:289-310. https://doi.org/10. 1016/j.marpetgeo.2017.04.004.

Liu J, Ding W, Yang H, Jiu K, Wang Z, Li A. Quantitative prediction of fractures using the finite element method: a case study of the Lower Silurian Longmaxi formation in northern Guizhou, South China. J Asian Earth Sci. 2018b;154:397-418. https://doi.org/10. 1016/j.jseaes.2017.12.038.

Liu J, Ding W, Yang H, Wang R, Yin S, Li A. 3D geomechanical modeling and numerical simulation of in situ stress fields in shale reservoirs: a case study of the Lower Cambrian Niutitang Formation in the Cen'gong Block, South China. Tectonophysics. 2017b;712:663-83.

Matsumoto N, Yomogida K, Honda S. Fractal analysis of fault systems in Japan and the Philippines. Geophys Res Lett. 1992;19:357-60. https://doi.org/10.1029/92GL00202.

Mirzaie A, Bafti SS, Derakhshani R. Fault control on $\mathrm{Cu}$ mineralization in the Kerman porphyry copper belt, SE Iran: a fractal analysis. Ore Geol Rev. 2015;71:237-47. https://doi.org/10. 1016/j.oregeorev.2015.05.015.

Mynatt I, Seyum S, Pollard DD. Fracture initiation, development, and reactivation in folded sedimentary rocks at Raplee Ridge, UT. J Struct Geol. 2009;31:1100-13. https://doi.org/10.1016/j.jsg. 2009.06.003.

Nelson RA. Geologic analysis of naturally fractured reservoirs. 2nd ed. Houston: Gulf Publishing Professional Publishing; 2001.

Neng Y, Qi J, Zhang C, Yang L, Zhang K. Structural evolution of Shigang fault and features of hydrocarbon accumulation in Jinhu Sag. Acta Pet Sin. 2009;30:667-71.

Neng Y, Qi J, Zhang C, Zhang K, Ren H, Zheng Y. Structural features of the Jinhu sag in the Subei Basin and its petroleum geological significance. Geotecton Metallog. 2012;36:16-23. 
Olson JE, Laubach SE, Lander RH. Natural fracture characterization in tight gas sandstones: integrating mechanics and diagenesis. Am Assoc Pet Geol Bull. 2009;93:1535-49. https://doi.org/10. 1306/08110909100.

Pan B, Yuan M, Fang C, Liu W, Guo Y, Zhang L. Experiments on acoustic measurement of fractured rocks and application of acoustic logging data to evaluation of fractures. Pet Sci. 2017;14:520-8. https://doi.org/10.1007/s12182-017-0173-2.

Prioul R, Jocker J. Fracture characterization at multiple scales using borehole images, sonic logs, and walkaround vertical seismic profile. Am Assoc Pet Geol Bull. 2009;93:1503-16. https://doi. org/10.1306/08250909019.

Qin JS. Variation of the permeability of the low-permeability sandstone reservoir under variable confined pressure. J Xian Pet Inst. 2002;17:28-31.

Sarp G. Evolution of neotectonic activity of East Anatolian Fault System (EAFS) in Bingöl pull-apart basin, based on fractal dimension and morphometric indices. J Asian Earth Sci. 2014;88:168-77. https://doi.org/10.1016/j.jseaes.2014.03.018.

Savage HM, Brodsky EE. Collateral damage: evolution with displacement of fracture distribution and secondary fault strands in fault damage zones. J Geophys Res. 2011;116:B03405. https://doi.org/10.1029/2010JB007665.

Seto M, Utagawa M, Katsuyama K, Nag DK, Vutukuri VS. In situ stress determination by acoustic emission technique. Int J Rock Mech Min Sci. 1997;34:281.e1-16. https://doi.org/10.1016/ S1365-1609(97)00156-1.

Shaw BE. Self-organizing fault systems and self-organizing elastodynamic events on them: geometry and the distribution of sizes of events. Geophys Res Lett. 2004;31:159-80.

Soleimani M. Naturally fractured hydrocarbon reservoir simulation by elastic fracture modeling. Pet Sci. 2017;14:286-301.

Strijker G, Bertotti G, Luthi SM. Multi-scale fracture network analysis from an outcrop analogue: a case study from the Cambro-Ordovician clastic succession in Petra, Jordan. Mar Pet Geol. 2012;38:104-16. https://doi.org/10.1016/j.marpetgeo. 2012.07.003.
Walker RJ, Holdsworth RE, Imber J, Ellis D. The development of cavities and clastic infills along fault-related fractures in tertiary basalts on the NE Atlantic margin. J Struct Geol. 2011;33:92-106. https://doi.org/10.1016/j.jsg.2010.12.001.

Wang W, Su Y, Zhang Q, Xiang G, Cui S. Performance-based fractal fracture model for complex fracture network simulation. Pet Sci. 2018;15:126-34. https://doi.org/10.1007/s12182-017-0202-1.

Wang Y, Li X, Zhao Z, Zhou R, Zhang B, Li G. Contributions of nontectonic micro-fractures to hydraulic fracturing-a numerical investigation based on FSD model. Sci China Earth Sci. 2016a;59:851-65.

Wang Z, Liu C, Zhang Y, Qu H, Yang X, Liu H. A study of fracture development, controlling factor and property modeling of deeplying tight sandstone in Cretaceous thrust belt $\mathrm{K}$ region of Kuqa depression. Acta Pet Sin. 2016b;32:865-76.

Willis-Richards J, Watanabe K, Takahashi H. Progress toward a stochastic rock mechanics model of engineered geothermal systems. J Geophys Res. 1996;101:17481-96. https://doi.org/10. 1029/96JB00882.

Zeng L, Li X-Y. Fractures in sandstone reservoirs with ultra-low permeability: a case study of the Upper Triassic Yanchang formation in the Ordos Basin, China. Am Assoc Pet Geol Bull. 2009;93:461-77.

Zeng L, Su H, Tang X, Peng Y, Gong L. Fractured tight sandstone oil and gas reservoirs: a new play type in the Dongpu depression, Bohai Bay Basin, China. Am Assoc Pet Geol Bull. 2013;97:363-77. https://doi.org/10.1306/09121212057.

Zhang S, Wang Y, Shi D, Xu H, Pang X, Li M. Fault-fracture mesh petroleum plays in the Jiyang Superdepression of the Bohai Bay Basin, Eastern China. Mar Pet Geol. 2004;21:651-68. https://doi. org/10.1016/j.marpetgeo.2004.03.007.

Zhao WT, Hou GT. Fracture prediction in the tight-oil reservoirs of the Triassic Yanchang formation in the Ordos basin, northern China. Pet Sci. 2017;14:1-23. https://doi.org/10.1007/s12182016-0141-2. 